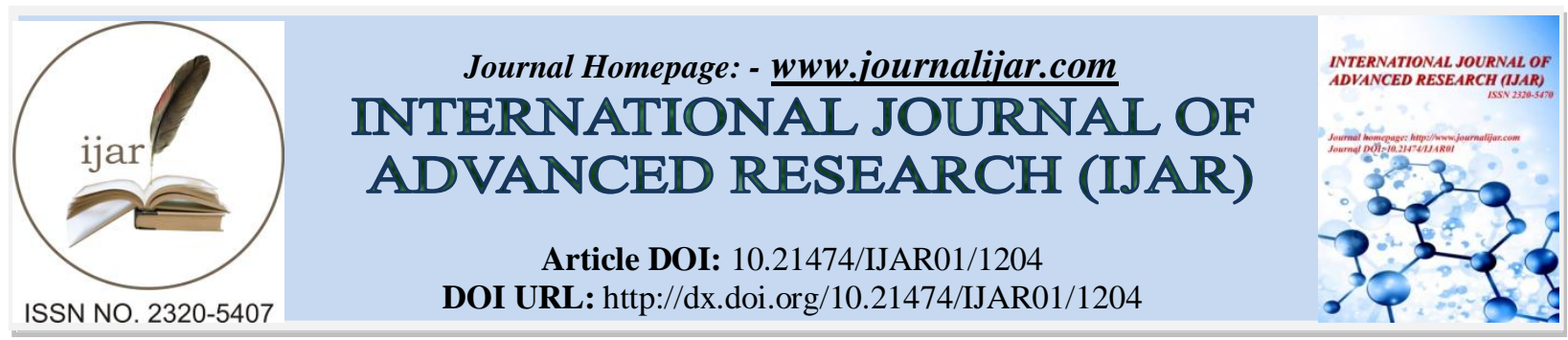

RESEARCH ARTICLE

\title{
EVALUATION OF DIFFERENT SILKWORM HYBRIDS IN JAMMU REGION.
}

\author{
Nirmal Singh ${ }^{* 1}$, J.S. Tara ${ }^{2}$, M.K. Tayal ${ }^{3}$, Avinder Kour ${ }^{1}$, Kalpana Sudan ${ }^{1}$, Kavita Sharma ${ }^{1}$, Vinod Kumar ${ }^{1}$, \\ Amit Sharma ${ }^{1}$ and Abdul Mahroof ${ }^{1}$. \\ 1. P.G. Department of Sericulture, Poonch Campus, University of Jammu. \\ 2. Department of Zoology, University of Jammu. \\ 3. Regional Sericulture Research Station, Miran Sahib, Jammu.
}

\section{Manuscript Info}

Manuscript History

Received: 12 June 2016

Final Accepted: 27 July 2016

Published: August 2016

Key words:-

Sericulture, silkworm rearing, silkworm hybrids, shell ratio, cocoon yield.

\begin{abstract}
The agro climatic conditions of Jammu and Kashmir State are most ideal for bivoltine silkworm rearing. However, quality cocoon production at commercial level has suffered mostly because of inadequate quality of leaves, due to lack of infrastructure facilities for silkworm rearing at farmers level, improper diffusion of technologies required for silkworm rearing at farmers level. Besides, these factors the silkworm race reared by farmers also affects the silkworm rearing. In this direction, the present study was undertaken and four different silkworm hybrids, namely; I) SH6 x NB4D2, II) Double Hybrid (CSR6 x CSR26) x (CSR2 x CSR27), III) FC1 (CSR6 x CSR26) IV) FC2 (CSR2 x CSR27) were selected for rearing in spring season during the year 2014. These four hybrids were reared at Regional Sericulture Research Station (RSRS), Miran Sahib, Jammu, in order to evaluate the performance of different silkworm hybrids in Jammu region. Results obtained during rearing of these hybrids showed that overall performance of CSR Double hybrid (CSR6 x CSR26) x (CSR2 x CSR27) was better over the other three silkworm hybrids.
\end{abstract}

Copy Right, IJAR, 2016,. All rights reserved.

\section{Introduction:-}

Jammu and Kashmir is the only traditional bivoltine belt in the country which because of its salubrious climate for silkworm rearing is capable of production of silk of international grade. Jammu and Kashmir State has been identified as one of the major constraints in boosting cocoon production (Trag et al., 1992). Generally, the two silkworm rearings are conducted in the state, spring and autumn. The spring rearing of Silkworm is quite popular in the state for quantity and quality bivoltine cocoon production. The second commercial rearing was conducted in autumn season but cocoon yield recorded was poor due to more disease incidence or crop loss during this season. Scientists are also working on possibilities of third silkworm rearing in autumn season in some parts of the Jammu region by using hardy Silkworm races. Different factors responsible for quality cocoon production are mulberry leaf $(38.2 \%)$, climate $(37 \%)$, rearing technique (9.3\%), silkworm race $(4.2 \%)$, silkworm eggs $(3.0 \%)$ and other factors $(8.2 \%)$ (Miyashita, 1986). The race of the silkworm reared also affects quality cocoon production. Scientists have recommended various bivoltine silkworm hybrids for commercial exploitation from time to time (Rajalakshmi et al ., 1998., 2000., Nirmal Kumar et al ., 1999., Malik et al 2001., Ramesh Babu et al ., 2002). 
The aim of the present investigation is to find out the most suitable silkworm hybrid for rearing in spring season in Jammu province from the various recommended hybrids for Jammu region.

The present rearing was conducted in RSRS, Miran sahib, Jammu in 2014, we have conducted spring silkworm rearing of four different silkworm hybrids namely SH6 x NB4D2, Double hybrid (CSR6 x CSR26) x (CSR2 x CSR27), FC1 (CSR6 x CSR26), FC2 (CSR2 x CSR27) on one mulberry variety namely S-146 which is one of the ruling variety of subtropical region.

\section{Material and methods:-}

The Silkworm rearing of four improved silkworm hybrids namely SH6 x NB4D2, Double hybrid (CSR6 x CSR26) $x$ (CSR2 x CSR27), FC1 (CSR6 x CSR26), FC2 (CSR2 x CSR27) was carried out by feeding on the mulberry variety S-146. The silkworm rearing was conducted as per the recommendation made by Krishnaswami (1978 b). 5 dfls per race were reared upto second moult, and after the second moult, 250 larvae in three replication were retained and various traits like weight of mature larvae, cocoon weight, shell weight, shell ratio, pupation rate \%, cocoon yield / 10,000 larvae (by number and weight),average filament length, denier and cocoon harvesting report etc were recorded.

\section{Results and discussion:-}

The results of current study revealed that the cocoon yield and economic traits viz weight of mature larvae, cocoon weight, shell weight, shell ratio $\%$, pupation rate $\%$, average filament length and denier were apparently influenced by silkworm breed. Four silkworm hybrids namely SH6 x NB4D2, Double hybrid (CSR6 x CSR26) x (CSR2 x CSR27), FC1 (CSR6 x CSR26), FC2 (CSR2 x CSR27) were evaluated by feeding on the ruling mulberry variety S146. The data was collected third instars onwards and the results are shown in (Table 1 and 2).

Table 1:- Showing the mean values of weight of 10 mature larvae $(\mathrm{g})$ single cocoon weight, single shell weight, weight of 10 mature larvae $(\mathrm{g})$, Pupation rate \%, average filament length $(\mathrm{m})$ and denier.

\begin{tabular}{|c|c|c|c|c|c|c|}
\hline RACE & $\begin{array}{c}\text { WT OF 10 } \\
\text { MATURE } \\
\text { LARVAE } \\
(\mathrm{g})\end{array}$ & $\begin{array}{c}\text { SINGLE } \\
\text { COCOON } \\
\text { WT }(\mathrm{g})\end{array}$ & $\begin{array}{c}\text { SINGLE } \\
\text { SHELL } \\
\text { WT }(\mathrm{g})\end{array}$ & $\begin{array}{c}\text { PUPATION } \\
\text { RATE \% }\end{array}$ & $\begin{array}{c}\text { AVERAGE } \\
\text { FILAMENT } \\
\text { LENGTH } \\
(\mathrm{m})\end{array}$ & DENIER \\
\hline SH6 $\times$ NB4D2 & 62.5 & 1.135 & 0.21 & 79 & 890 & 2.02 \\
\hline Double hybrid & 72.5 & 2.03 & 0.45 & 90 & 986 & 2.20 \\
\hline FC2 & 60 & 1.77 & 0.38 & 85 & 1020 & 2.17 \\
\hline FC1 & 61.5 & 1.73 & 0.37 & 89 & 998 & 2.03 \\
\hline
\end{tabular}

The data with regard to weight of 10 mature larvae varied from $60 \mathrm{~g}$ (FC2) to $72.5 \mathrm{~g}$ in (Double hybrid) (Table1). Single cocoon weight ranged from $1.13 \mathrm{~g}$ to $2.03 \mathrm{~g}$ in SH6 X NB4D2 and Double hybrid, respectively. Single shell weight was found to be highest in Double hybrid and lowest in SH6 X NB4D2 (Table1). High pupation rate was noticed in double hybrid followed by FC1, FC2 and SH6 X NB4D2. The filament length ranged from a minimum of $890 \mathrm{~m}$ (SH6 X NB4D2) to maximum of $1020 \mathrm{~m}$ (FC2). The overall mean filament size recorded thickness of $2.20 \mathrm{~d}$ in Double hybrid to thin size of $2.02 \mathrm{~d}$ in SH6 X NB4D2 (Table1). The weight and number of good cocoons was found to be higher in Double hybrid followed by FC1 and other silkworm hybrids (Table 2).

Table 2:- Mean values of good cocoons (number and weight) and defective cocoon (number and weight) out of 250 cocoons each.

\begin{tabular}{|l|l|l|l|l|l|l|l|l|}
\hline Race & \multicolumn{2}{|c|}{ Good cocoons } & \multicolumn{2}{c|}{ Flimsy cocoons } & \multicolumn{2}{c|}{ Double cocoons } & \multicolumn{2}{c|}{ Mute cocoons } \\
\hline & NO. & Wt.(g) & NO. & Wt.(g) & NO. & Wt.(g) & NO. & Wt.(g) \\
\hline SH6 x NB4D2 & 179 & 332 & 4 & 7 & 2 & 6 & 2 & 6 \\
\hline Double Hybrid & 220 & 430 & 4 & 10 & 2 & 4 & 1 & 2 \\
\hline FC2 & 192 & 403 & 6 & 10 & 2 & 6 & 6 & 8 \\
\hline FC1 & 218 & 418 & 7 & 9 & 3 & 6 & - & - \\
\hline
\end{tabular}

In terms of shell ratio \% Double hybrid dominate all the silkworm hybrids (Fig.1) Cocoon yield/10,000 larvae by number was higher in FC1 and by weight it was dominated by Double hybrid followed by FC1 and dominate the other Silkworm hybrids (Fig.2). 


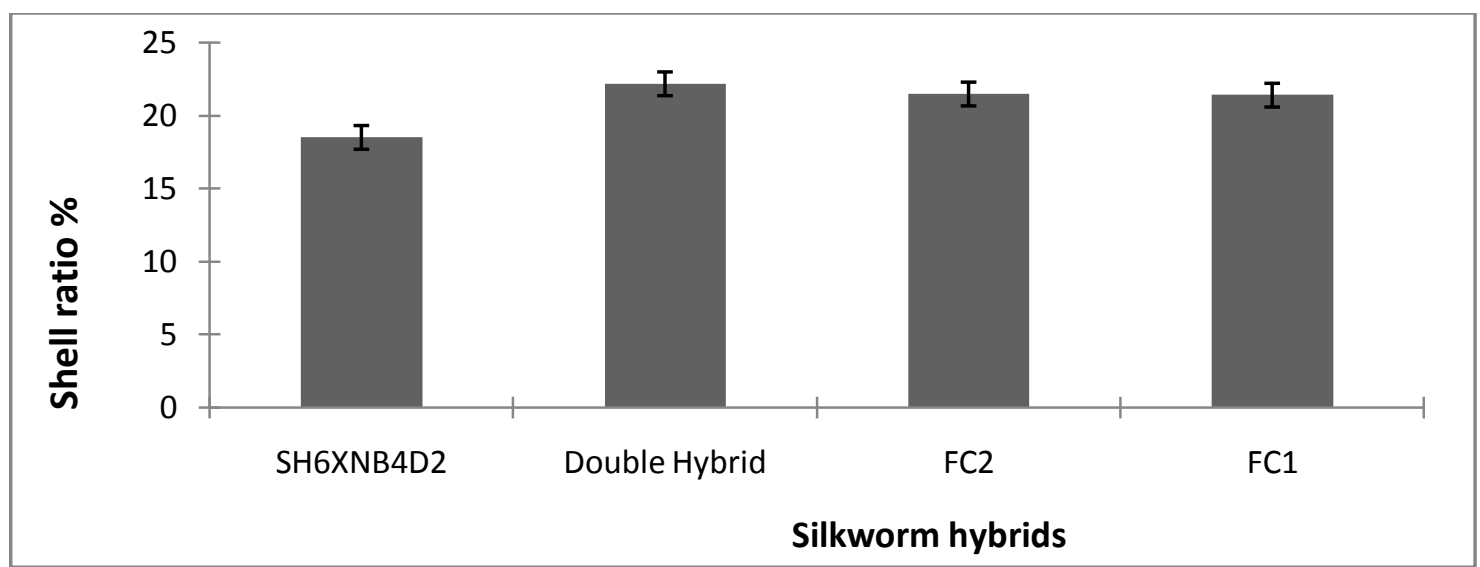

Fig. 1:- Shell ratio \% in different silkworm hybrids. Vertical bars show \pm standard error of the mean.

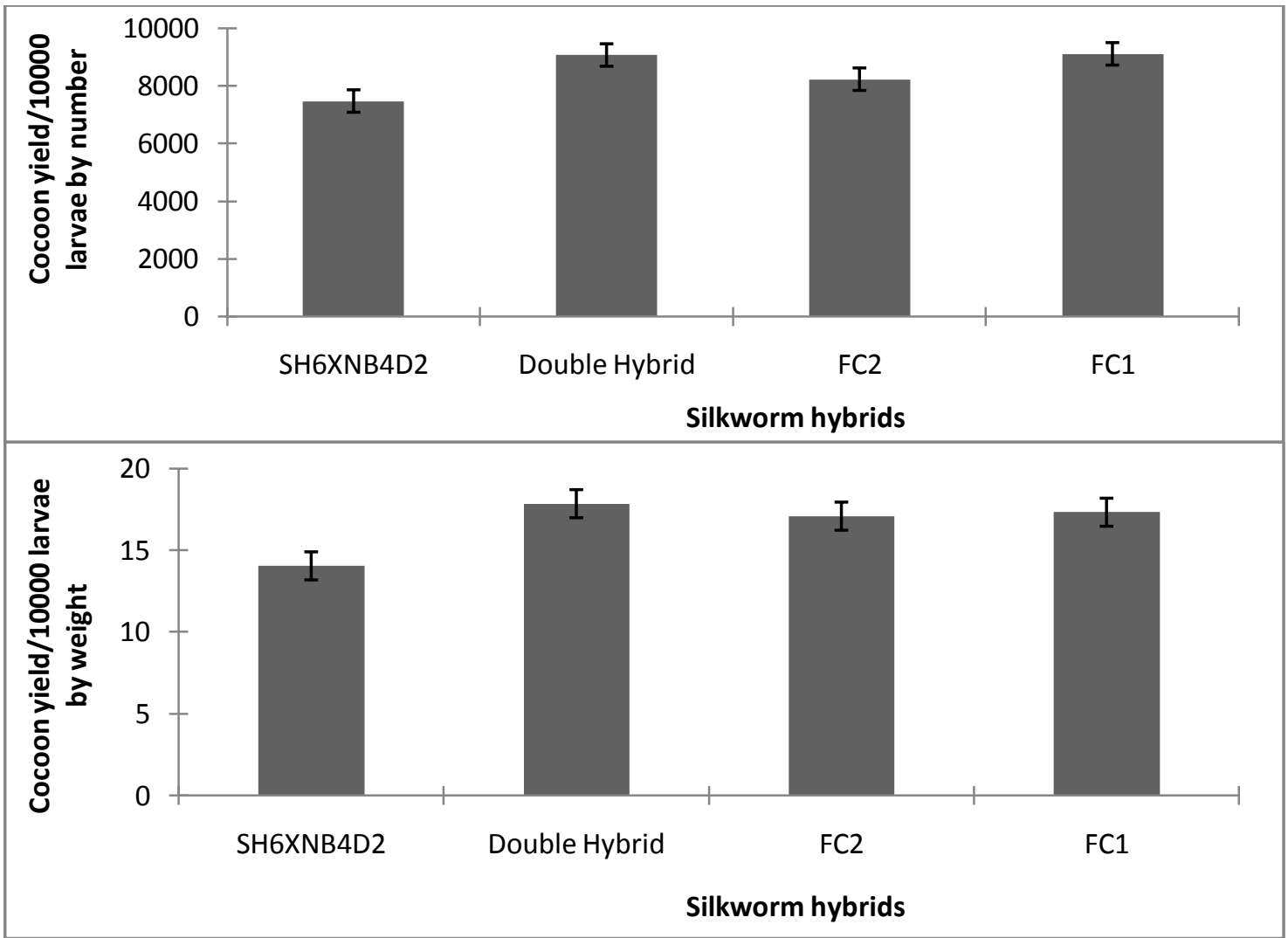

Fig. 2:- Cocoon yield / 10000 larvae in different silkworm hybrids by number and by weight. Vertical bars show \pm standard error of the mean.

Overall results show that the performance of Double hybrid was good and performed well during the spring season than the other three silkworm hybrids. Many studies have reported the superiority of double hybrids over single hybrids (Ashoka and Govindan, 1994; Bindroo et al., 2014) and results of the present study are in conformity with the findings of these studies. The present study also recommends the rearing of double hybrid for commercial exploitation during spring rearing in Jammu region.

\section{Acknowledgement:-}

The authors are highly thankful to Joint Director, Regional Sericulture Research Station (RSRS), Miran Sahib, Jammu for rendering all help and guidance from time to time and extending the various facilities during the present investigation. 


\section{References:-}

1. Ashoka, J and Govinddan, R. 1994. Performance of some Bivoltine Silkworm breeds and their Single and Double cross hybrids for yield and cocoon traits. Karnataka Journal of Agriculture Sciences, 7 (1): 28-31.

2. Bindroo, B.B.; Begum, A. N. and Reddy, N. M. 2014. New Bivoltine Silkworm Double hybrid, JAYACHAMARAJA (CSR50 X CSR52) X (CSR51 X CSR53) for high egg recovery, crop stability and Silk productivity, Technical Bulletin No. 10, Central Sericulture Research and Training Institute (Central Silk Board, Ministry of Textiles, Govt. of India).

3. Krishnaswami, S. 1978, new technology of Silkworm rearing. Bulletin No. 2, pp 1-23 Central Sericultural Research and Training Institute, Mysore.

4. Malik, G.N., Kamili, A.S.,Wani Shafiq, A., Munshi, N.A. and Tariq, A. (2001) Performance of some bivoltine silkworm Bombyx mori L. hybrids. Sericologia, 6: 105-111.

5. Miyashita, V., 1986. A report on mulberry cultivation and trainings methods suitable to bivoltine rearing in Karnataka, Central Silk Board, Bangalore, India.

6. Nirmal Kumar S, Ramesh Babu M, Basavaraja HK, Mal Reddy N, Datta RK. (1998). Double hybrids for improvement in silk production in silkworm, Bombyx mori L. silkworm Breeding. Oxford and IBH publishing Co. Pvt. Ltd., New Delhi, India, , 209-211.

7. Rajalakshmi, E., Chauchan T.P.S. and Kamble, C.K. (1998) Hybrid vigour among newly evolved bivoltine hybrids of silkworm, Bombyx mori L. under hill conditions. India. J. Seric., 68 :620-624.

8. Rajalakshmi, E; Chauchan T.P.S; Kamble, C.K. Srinivas, B.T and Mahadevaiah, C.M. (2000) Evaluation of newly evolve Bivoltine hybrids of Bombyx mori L. for silk yield contributing traits under hill conditions. Indian. J. Seric, 39(1):21-23.

9. Ramesh Babu, M., Chandrashekhariah, Lakshmi, H. and Prassad, J. (2002) Multiple trait evaluation of bivoltine hybrids of silkworm, Bombyx mori L. Int. J. Indust. Entomol., 5:37-44.

10. Trag AR, Kamili AS, Malik GN, Kukillo FA (1992).Evolution of high yielding bivoltine Silkworm (Bombyx mori L.) genotypes. Sericologia 32(2):321-337 